\title{
AN EXPERIMENTAL STUDY OF THE HERSCHEL-QUINCLE (HQ) TUBE NOISE ATTENUATION PERFORMANCE
}

\author{
Abdul-Hafid El-Majani ${ }^{1}$, Mohamed S. Oun ${ }^{2}$ and Salem A. Farhat ${ }^{3}$ \\ ${ }^{1,2,3}$ Department of Mechanical, Faculty of Engineering, University of Tripoli, Tripoli-Libya \\ 1am.mjani@yahoo.com
}

\begin{abstract}
The work presented in this paper summarize both analytical and experimental investigations of the Herschel-Quincke (HQ) concept for reducing known radiated inlet noise using signal generating system. The analytical part of this work involves one-dimensional plane wave propagate in a cylindrical duct. In this paper adaptive HQ tube is used to reduce tonal noise propagating as plane waves in closed end duct. The effect of HQ tube length on the noise reduction, induced by a loudspeaker at various frequencies, is investigated experimentally in an acoustically cylindrical duct with and without HQ. Five HQ tubes with different lengths are investigated. The distance between the HQ tube ends is kept constant $(\mathrm{l}=20 \mathrm{~cm}),\left(\mathrm{L}_{\mathrm{HQ}} / \mathrm{l}=1.5,2.5,3,3.5\right.$, and 4). Two Microphones system was used to measure the net acoustic power transmission in the duct. One microphone is located just before the HQ tube in the duct, and the other is at the closed end of the duct where it is always anti-node pressure. Data acquisition, monitoring and analysis are done using National Instrument DAQ card and LabVIEW software. A LabVIEW vi code is developed to interface and process the two microphones system signals. Results showed that the length of the HQ tube is very important for a passive control of the noise reduction. While long HQ tube was effective in noise reduction in low frequencies, short HQ tube was more effective for high frequencies.
\end{abstract}

Keywords: Herschel-Quincke, Acoustics, passive control, signal processing

\section{Introduction}

The concept of Herschel Quincke (HQ) tube as a noise reduction device; which is known since the beginning of the 20th century; has shown its potential to reduce the noise at some specific frequencies.

HQ-tube (Selamet, and et al., 1994) is, as shown in figure (1), a tube attaches to the main duct at two points along its axis. When an incident plane-wave travels in the duct to the right and encounters the first branch, named the inlet of HQ-tube, divides and will recombined later at the second intersection, named the outlet of HQ-tube. A phase shift between the recombined signals and consequently attenuation or reduction of sound will be created by changing HQ-tube parameters at a number of discrete frequencies. 
Noise control strategies can be characterized as active, passive, or a combination of both passive and active approaches. A Herschel-Quincke (HQ) tube is one of the passive noise control techniques.

Studies of Herschel-Quincke (HQ) tube for varying lengths and cross sectional areas, has been carried out since the $19^{\text {th }}$ century, first by Herschel and Quincke Herschel (1833) and Quincke (1866) and later refined by Stewart (1928), Stewart, and et al (1930) and Stewart, G. W. (1945) in the early $20^{\text {th }}$ century.

The Herschel-Quincke (HQ) tube concept consists of installing circumferential arrays of HQ tubes around the inlet and/or the by-pass duct of a turbofan engine. The application of HQ tubes to turbofan engine inlet noise is a developing technique originally pioneered at (Virginia Tech Jerome, and et al., 2002).

Taleb et al (2017) investigate the effect of the HQ (Herschel-Quincke) tube length on the reduction of noise. An acoustically cylindrical duct with and without HQ induced by a loudspeaker at various frequencies. Microphone system has been used to measure the net acoustic power transmission in the duct downstream with HQ tube and compared in the duct without the HQ tube. The cylindrical duct is an open-open end, with a wall thickness of 0.25 $\mathrm{cm}$, and has a length and inner diameter of $107 \mathrm{~cm}$ and $20 \mathrm{~cm}$ respectively. There are two types of HQ tubes mounted on the side of the duct, in the first; is a short HQ tube with a length of 14 $\mathrm{cm}$, and its diameter of $4 \mathrm{~cm}$. Tube is fixed at $59 \mathrm{~cm}$ from the loudspeaker. The other; is the long HQ tube with length of $72 \mathrm{~cm}$, and with a diameter of $4 \mathrm{~cm}$, this type of HQ is fixed at 31 $\mathrm{cm}$ from the loudspeaker. In their study the distance between the inlet and the outlet of the HQ was changed. In this paper the HQ-tube length is changed to study its effect on the performance of the HQ-tube attached to a closed end duct.

\section{Experimental setup}

A diagram of the experimental setup is shown in figure 1. In this case of study cylindrical tube with a single HQ tube is used to decrease the noise as shown in figure (1). Basically, the test rig consists of a cylindrical tube with and without HQ tube, a signal generator system, and a microphone system. The cylindrical tube is a closed end, and the other end is closed by a vibrating diaphragm of a loudspeaker, the tube has a length and an inner diameter of $1.0 \mathrm{~m}$ and $0.12 \mathrm{~m}$ respectively. The HQ tubes with inner diameter of $35 \mathrm{~mm}$, and with different length (LHQ) have been used, the distance between the HQ tube ends (l) is $20 \mathrm{~cm}$, in this paper; $L_{H Q} / l$ $=1.5,2.5,3,3.5$, and 4 are used. The closed tube is acoustically excited by a signal generating system, includes a signal generator (type Peak Tech.), an amplifier, and a loudspeaker. The amplitude of the supply voltage for the loudspeaker is kept constant during these experiments, the loudspeaker has a maximum power of $250 \mathrm{~W}$ and a frequency range of 20 to $4000 \mathrm{~Hz}$. Its effective diaphragm radius is $0.06 \mathrm{~m}$; sinusoidal signal mode has been selected to excite air in the tube. Almost every acoustic measurement arrangement contains microphones that normally 
convert sound pressures into electrical signals; an electrostatic (capacitor) type of microphone is used in these experiments for the measurement of sound pressure. The microphone is mounted at the closed end of the tube as shown in the Figure 1, a pre-amplifier and an amplifier used to amplify the captured signal by microphone from few milli-volts to few volts. National Instrument DAQ card and LabVIEW software have been applied for data acquisition, monitoring and analyses.

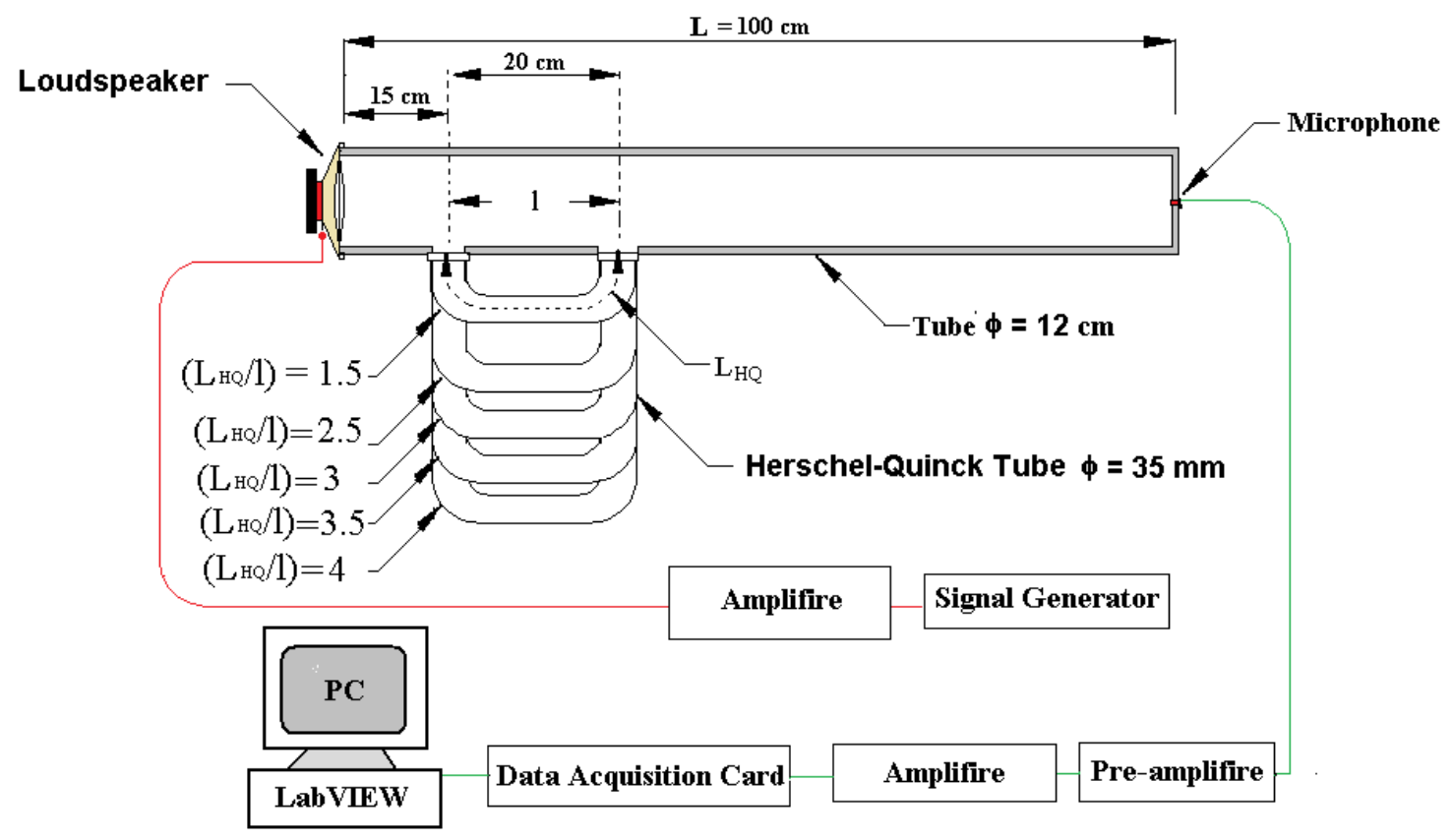

Figure (1): Schematic diagram of test rig

\section{Solution of Wave Equation for Air in a Close Top Tube and Closed by a Vibrating Diaphragm at the Bottom End}

Considered here that the sound field in a rigid tube that is closed at one end by a vibrating diaphragm of a loudspeaker with rms velocity of $u_{o}$, the other end is closed. The boundary condition at $\mathrm{z}=0$, the fluid velocity at the diaphragm face is equal to the velocity of the diaphragm $\left(\mathrm{u}_{\mathrm{o}}\right)$ (Temkin, S., 1981)

The total length of the tube is $\mathrm{L}$, and $\lambda$ is a wavelength, one solution which will satisfy the wave equation is given by the superposition of the complex pressure associated with a positive-going and negative going plane wave. Thus.

$$
p(z, t)=A e^{-j(k z-\omega t)}+B e^{j(k z+\omega t)}
$$

Where $A$ and $B$ are arbitrary complex number which represent the amplitude and relative phases of the wave travelling in the positive and negative direction respectively. The magnitudes of $A$ 
and $B$ are determined from boundaries conditions. When the magnitude of the velocity along tube is zero, the magnitude of the pressure is at the maximum, and vice versa.

From Euler's equation for plane wave

$$
u(z, t)=-\frac{1}{j \omega \rho_{o}} \frac{\partial p}{\partial z}
$$

the derivative of $p$ in equation (1) with respect to $\mathrm{z}$ :

$$
\frac{\partial p}{\partial z}=-j A k e^{-j(k z-\omega t)}+j B k e^{j(k z+\omega t)}
$$

and substitute into Euler's Equation (2):

$$
u(z, t)=\frac{k}{\rho_{o} \omega}\left(A e^{-j(k z-\omega t)}-B e^{j(k z+\omega t)}\right)
$$

Since $k=\frac{\omega}{c_{o}}$, where $\mathrm{c}$ is speed of sound in fluid, expression can be simplified:

$$
u(z, t)=\frac{1}{\rho_{o} c_{o}}\left(A e^{-j(k z-\omega t)}-B e^{j(k z+\omega t)}\right)
$$

the boundaries conditions are;

$$
\begin{aligned}
& \left.\frac{\partial p}{\partial z}\right|_{z=L^{\prime}}=0 \\
& \mathrm{u}=0 \text { at } \mathrm{Z}=\mathrm{L} \\
& \mathrm{u}=\mathrm{u}_{\mathrm{o}} \text { at } \mathrm{Z}=0
\end{aligned}
$$

$$
\begin{array}{r}
A-B=u_{o} c_{o} \rho_{o} \\
A=\frac{u_{o} c_{o} \rho_{o} e^{j k l}}{2 j \sin k l} \quad \text { and } \quad B=\frac{u_{o} c_{o} \rho_{o} e^{-j k l}}{2 j \sin k l} \\
u(z, t)=\frac{\omega l}{\sin k l} \cos \omega t \sin (k(L-z))
\end{array}
$$


the corresponding acoustic pressure is;

$$
p^{\prime}(z, t)=c_{o} \rho_{o} \frac{\omega l}{\sin k l} \sin \omega t \cos (k(L-z))
$$

Pressure Fluctuating P'(z,t)

$$
\begin{aligned}
& P(z, t)=\bar{p}+p^{\prime} \\
& p(z, t)=p^{\prime}
\end{aligned}
$$

$$
\begin{gathered}
\overline{p^{\prime 2}}={ }_{T} \underset{\lim _{\infty}}{ } \frac{1}{T} \int_{0}^{T} p^{\prime 2} d t \quad \text { [ref] } \\
p^{\prime}(z, t)=c_{o} \rho_{o} \frac{\omega l}{\sin k l} \sin \omega t \cos (k(L-z)) \\
p^{2^{\prime}(z, t)}=\left(c_{o} \rho_{o} \frac{\omega l}{\sin k l} \sin \omega t \cos (k(L-z))\right)^{2} \\
\overline{p^{2}(z, t)}=\frac{1}{T} \int_{0}^{T}\left(c_{o} \rho_{o} \frac{\omega l}{\sin k l} \sin \omega t \cos (k(L-z))\right)^{2} d t \\
\overline{p^{2}(z, t)}=\frac{1}{T} \int_{0}^{T}\left(c_{o} \rho_{o} \frac{\omega l}{\sin k l} \cos (k(L-z))\right)^{2} \sin ^{2} \omega t d t
\end{gathered}
$$

$$
\begin{aligned}
& \sin ^{2} \omega t=\frac{1}{2}(1-\cos 2 \omega t) \\
& \overline{p^{2}(z, t)}=\frac{1}{T} \int_{0}^{T}\left(c_{o} \rho_{o} \frac{\omega l}{\sin k l} \cos (k(L-z))\right)^{2} \sin ^{2} \omega t d t \\
& \sin ^{2} \omega t=\frac{1}{2}(1-\cos 2 \omega t) \\
& \overline{p^{2}(z, t)}=\frac{1}{T}\left(c_{o} \rho_{o} \frac{\omega l}{\sin k l} \cos (k(L-z))\right)^{2}\left(\frac{1}{2}\left(t-\frac{\sin 2 \omega t}{2 \omega}\right)\right)_{0}^{T}
\end{aligned}
$$




$$
\overline{p^{2}(z, t)}=\left(c_{o} \rho_{o} \frac{\omega l}{\sin k l} \cos (k(L-z))\right)^{2}\left(\left(\frac{1}{2}-\frac{\sin 2 \omega T}{4 \omega}\right)\right)
$$

Root mean square of Pressure fluctuating Prms

$$
\begin{aligned}
& P_{r m s}=\sqrt{p^{2}(z, t)}=\left(c_{o} \rho_{o} \frac{\omega l}{\sin k l} \cos (k(L-z))\right) \sqrt{\left(\left(\frac{1}{2}-\frac{\sin 2 \omega T}{4 \omega T}\right)\right)} \\
& P_{r m s}(z=L)=\left(c_{o} \rho_{o} \frac{\omega l}{\sin k l}\right) \sqrt{\left(\left(\frac{1}{2}-\frac{\sin 2 \omega T}{4 \omega T}\right)\right)}
\end{aligned}
$$

Normalized acoustic pressure to the Prms at $\mathrm{z}=\mathrm{L}$

$$
\begin{gathered}
\frac{p_{r m s}(z)}{p_{r m s}(L)}=\left|\left(\cos \left(k\left(L^{\prime}-z\right)\right)\right)\right| \\
k=\frac{2 \pi}{\lambda}, \lambda=\frac{c_{o}}{f}, k=\frac{\omega}{c_{o}}, \text { and } c_{o}=\sqrt{\gamma R T}
\end{gathered}
$$

\section{where:}

$\mathrm{k}$ is the wave number

$\omega$ is the angular frequency $[\mathrm{rad} / \mathrm{s}]$

$\lambda$ is the wave length [m]

$c_{o}$ is the speed of the sound $[\mathrm{m} / \mathrm{sec}]$

$f$ is the frequency $[\mathrm{Hz}]$

$\mathrm{R}$ is the gas constant $\left[\frac{J}{\mathrm{~kg} \cdot K}\right]$

$\gamma$ is the specific heat ratio

$\mathrm{T}$ is the temperature $[\mathrm{K}]$

For closed tube at the end 


$$
\lambda_{n}=\frac{4 L}{(2 n-1)} \quad \mathrm{n}=1,2,3,4,5, \ldots \ldots \ldots
$$

$\mathrm{L}$ is the tube length $[\mathrm{m}]$

$$
f_{n}=(2 n-1) f_{1}
$$

Figure (2) shows the variation of the normalised pressure $\left(p_{r m s}(z) / p_{r m s}(L)\right)$ variations as a function of the tube length for first six modes, by using Eq. 9. At $\mathrm{z}=0$, the $r m s$ velocity is $u_{o}$ and at $\mathrm{z}=L, \partial P / \partial z=0$, the period $T=1 / f$.

The fundamental mode of this tube is $85 \mathrm{~Hz}$, high order modes using equation $10,(255 \mathrm{~Hz}, 425$ $\mathrm{Hz}, 595 \mathrm{~Hz}, \ldots \ldots . .$.

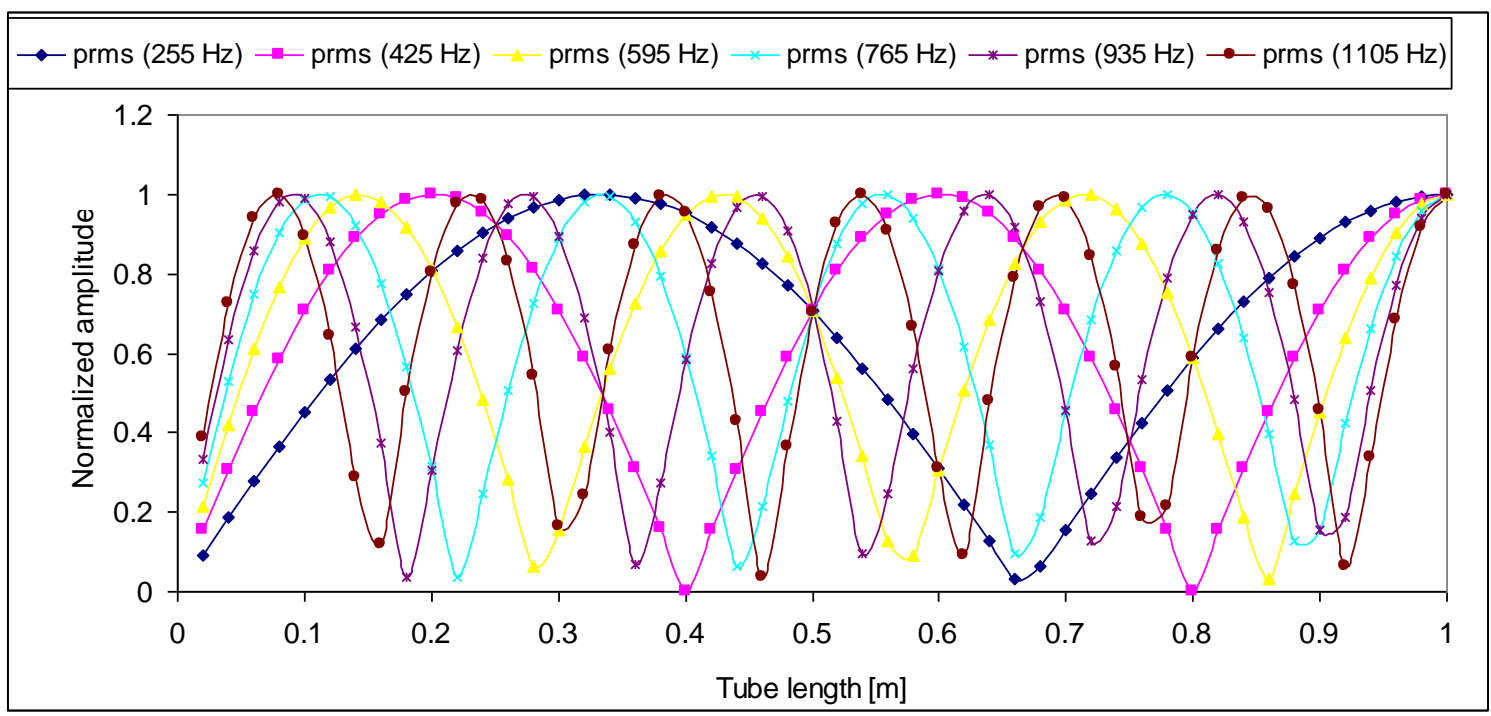

Figure (2): six theoretical acoustic pressure modes along the tube

\section{Experimental Measurements of the Tube Harmonics}

To evaluate the relative amplitude of $r m s$ acoustic pressure at different excitation frequencies, the rms pressure at the pressure anti-node is measured using a microphone system, which is located at the closed end of the tube, because this location always has maximum rms acoustic pressure amplitude for all harmonics, whereas the other pressure anti-node locations vary along the tube with the excitation frequencies. The excitation frequency applied was varied from 20 $\mathrm{Hz}$, which is the lowest frequency response of the loudspeaker, to $2500 \mathrm{~Hz}$. The voltage applied to the loudspeaker was maintained at 8 volts. By using the data acquisition system, the digital signal generator is connected to the loudspeaker through a digital to analogue (D/A) channel and the signals picked up by the microphone which is connected to the data acquisition system 
through the analogue to digital (A/D) channel. Figure (3) presents the rms pressure in volts as a function of excitation frequency. It can be seen from the figure that the first pressure rms peak appears at $85 \mathrm{~Hz}$ which represents the fundamental mode of this rig. The second peak appears at $245 \mathrm{~Hz}$, which represents the second mode and third mode at $408 \mathrm{~Hz}$ fourth mode at 570 $\mathrm{Hz}$......etc. It is also clearly seen that the ratio between all the peaks is 1: 2: 3: ..., and so on, which is in a good agreement with the theoretical analysis of the wave equation of acoustic pressure.

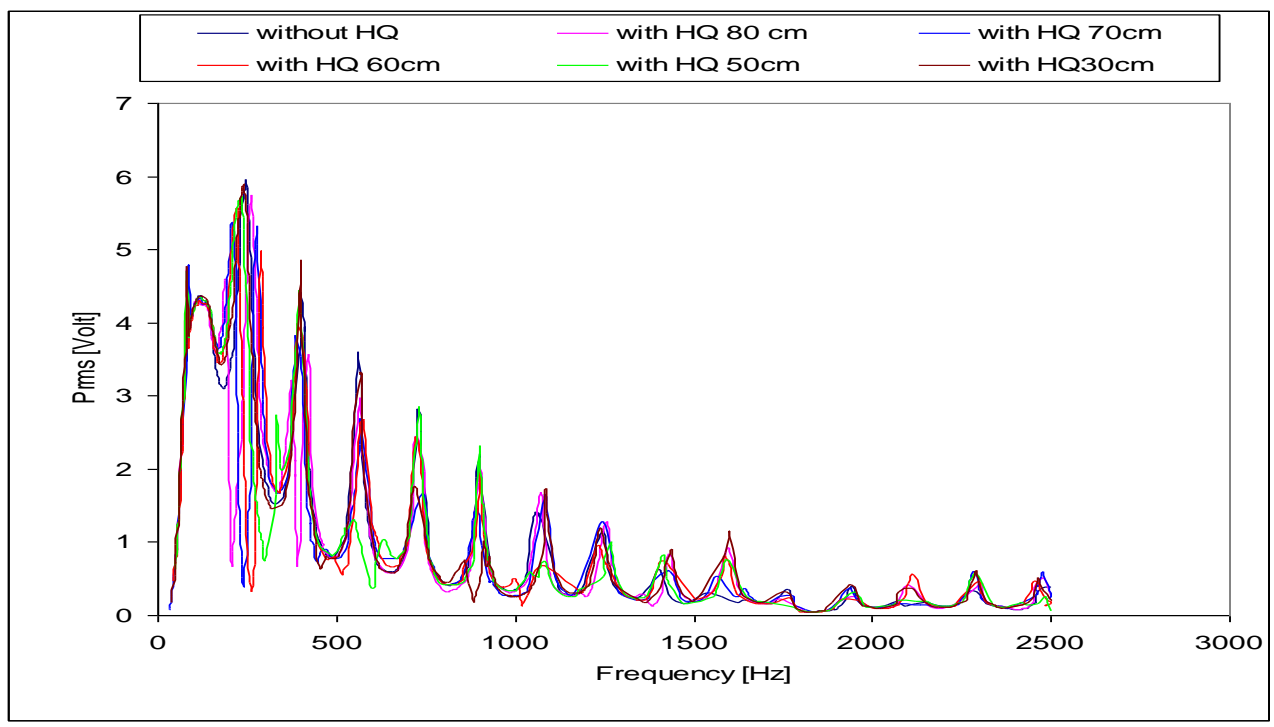

Figure (3): The rms acoustic pressure as a function of the excitation frequency $\left(f_{e}\right)$.

Figure (4) illustrates the first six wave modes of the measured rms pressure along the tube. The rms pressure is measured using a microphone, which is moving along the tube whilst keeping the loudspeaker at a constant power. From the figure the maximum rms acoustic pressure amplitude for all harmonics at the closed end of the tube, whereas the other pressure anti-node locations vary with the excitation frequency. The trends of the modes are very close to the theoretical calculation of the closed end tube with an end-mounted loudspeaker. From the Figure, it can also be seen that the pressure fluctuations ( $r m s$ ) are periodic along the tube. For this reason, this will be analyzed further, in this paper, in terms of time series history and power spectrum. 


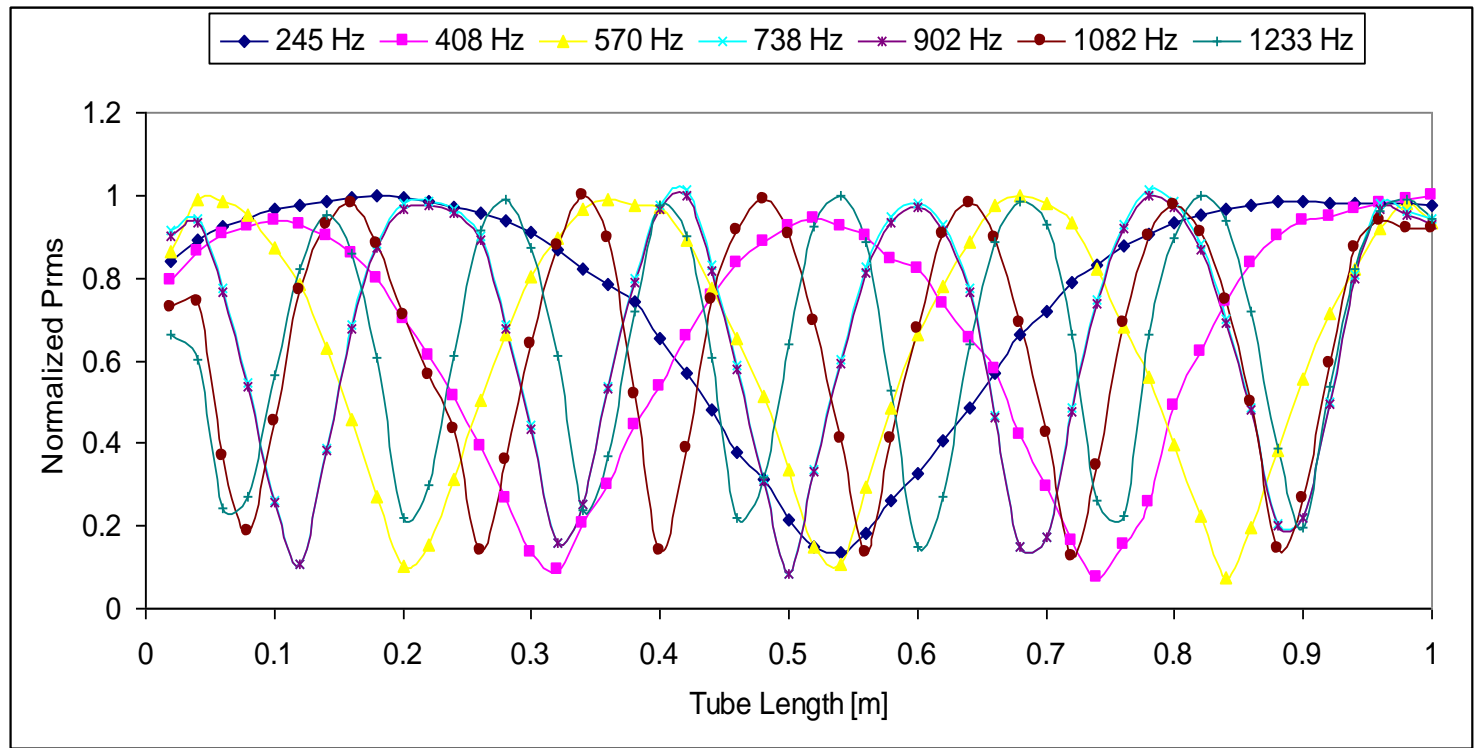

Figure (4): First seven experimental acoustic pressure modes of the tube (n=2,3,4,5,6,7, and 8)

The HQ tubes with inner diameter of $35 \mathrm{~mm}$, and with different length ( $\left.\mathrm{L}_{\mathrm{HQ}}\right)$ have been used, the distance between the HQ tube ends is $(l)=20 \mathrm{~cm}$, in this paper; $L_{H Q} / l=1.5,2.5,3,3.5$, and 4 are used. Figure (5) shows the zoom-in of the second beak shown in figure 3. It can be seen that the HQ-tube length has a significant effect on the noise reduction where at low frequency of $206 \mathrm{~Hz}$ the longest HQ-tube $(80 \mathrm{~cm})$ was the most effective with reduction of $80.9 \%$. While the shorter length of $60 \mathrm{~cm}$, at the same frequency $(206 \mathrm{~Hz})$ was less effective.

As the frequency increases the reduction noise was most effective with shorter HQ-tube length e.g. at frequency of $263 \mathrm{~Hz}$ the maximum reduction (93.1\%) with HQ-tube length of $60 \mathrm{~cm}$. For all HQ-tube lengths tested in this work the reduction of noise in the second beak is summarized in table (1). From this table it can be seen that the shorter lengths of HQ-tube $(20$ and $30 \mathrm{~cm})$, the pressure fluctuation (rms) are higher than that without HQ-tube with a percent of 4.63 and 19.11 respectively.

Table (1): reduction of the noise with and without HQ at the second peak

\begin{tabular}{|c|c|c|c|c|c|}
\hline \multicolumn{7}{|c|}{ Second Peak (Second Harmonic) } \\
\hline $\begin{array}{c}\text { HQ length } \\
{[\mathbf{c m}]}\end{array}$ & $\begin{array}{c}\text { without } \\
\text { HQ }\end{array}$ & $\begin{array}{c}\text { with } \\
\text { HQ }\end{array}$ & $\begin{array}{c}\text { Excitation } \\
\text { Frequency }\end{array}$ & $\begin{array}{c}\text { Reduction } \\
\text { percentage }\end{array}$ & state \\
\hline 30 & 5.64 & 5.901 & 238 & -4.62766 & Increase \\
\hline 50 & 4.7768 & 5.69 & 227 & -19.1174 & Increase \\
\hline 60 & 4.7369 & 0.3228 & 263 & 93.18542 & Decrease \\
\hline 70 & 5.65 & 0.392 & 237 & 93.06195 & Decrease \\
\hline 80 & 3.54 & 0.6738 & 206 & 80.9661 & Decrease \\
\hline
\end{tabular}




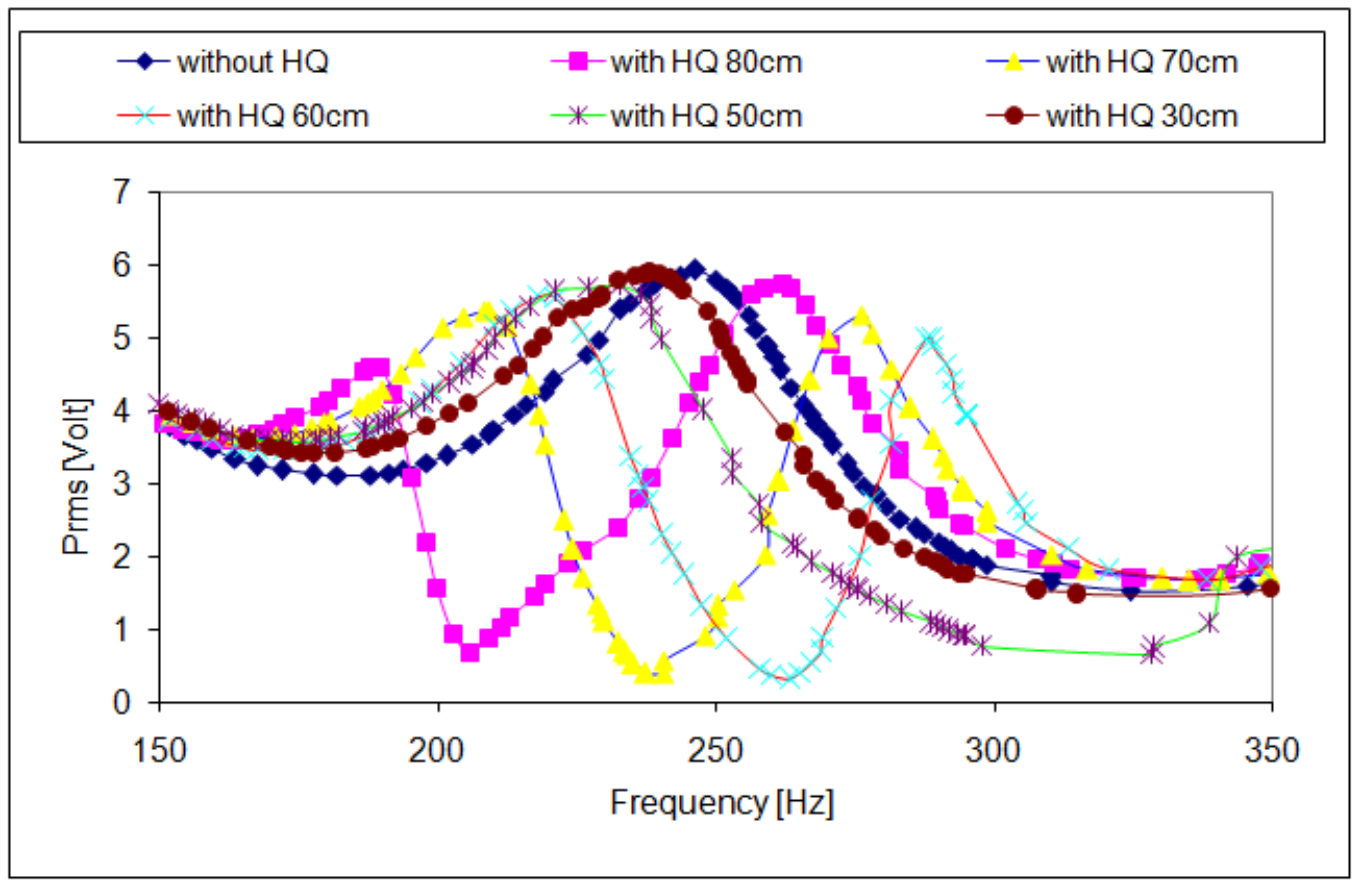

Figure (5): The zoom-in of the second beak in the Figure (3)

Figures (6), (8), and (10) show the time series with signal amplitude. These figures show that the received signal by microphone is a sine wave, the same as the applied signal at different HQ-tube length of 60, 70, and $80 \mathrm{~cm}$ and without HQ. The reduction in the noise by all HQ-tube lengths is seen very clearly in these figures. Results show that all the signals have a sinusoidal form, but with HQ the signal is less in amplitude due to the reduction effect.

Figures (7), (9), and (11) show the power spectrum of the signals for all HQ-tube lengths tested and without the HQ-tube. The signals are rigorously analyzed by using LabVIEW software. The analysis is done on the basis of time history and power spectrum. The sampling rate is 5000 samples per second and the duration of each sampling is 4 second. (Number of samples is 20,000).

Results of power spectrum show that, only one peak at the same applied frequency of signal generator, and also here less amplitude of power spectrum with HQ tube, that means the signals are very pure signal without any sub-harmonics and with reduction in noise by using the HQ technique. 


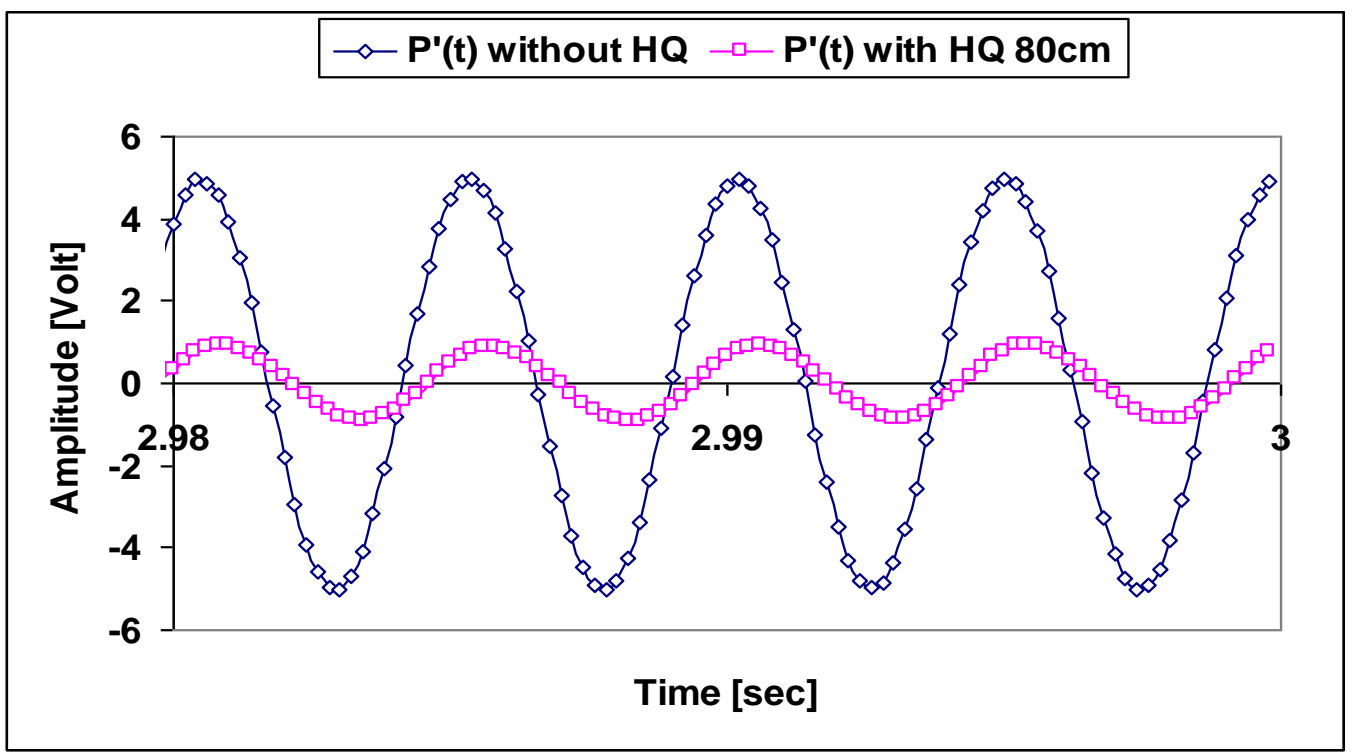

Figure (6): Time history of the acoustic signals, without and with the longest $H Q$ at frequency of $206 \mathrm{~Hz}$. HQ-Tube length of $80 \mathrm{~cm}$

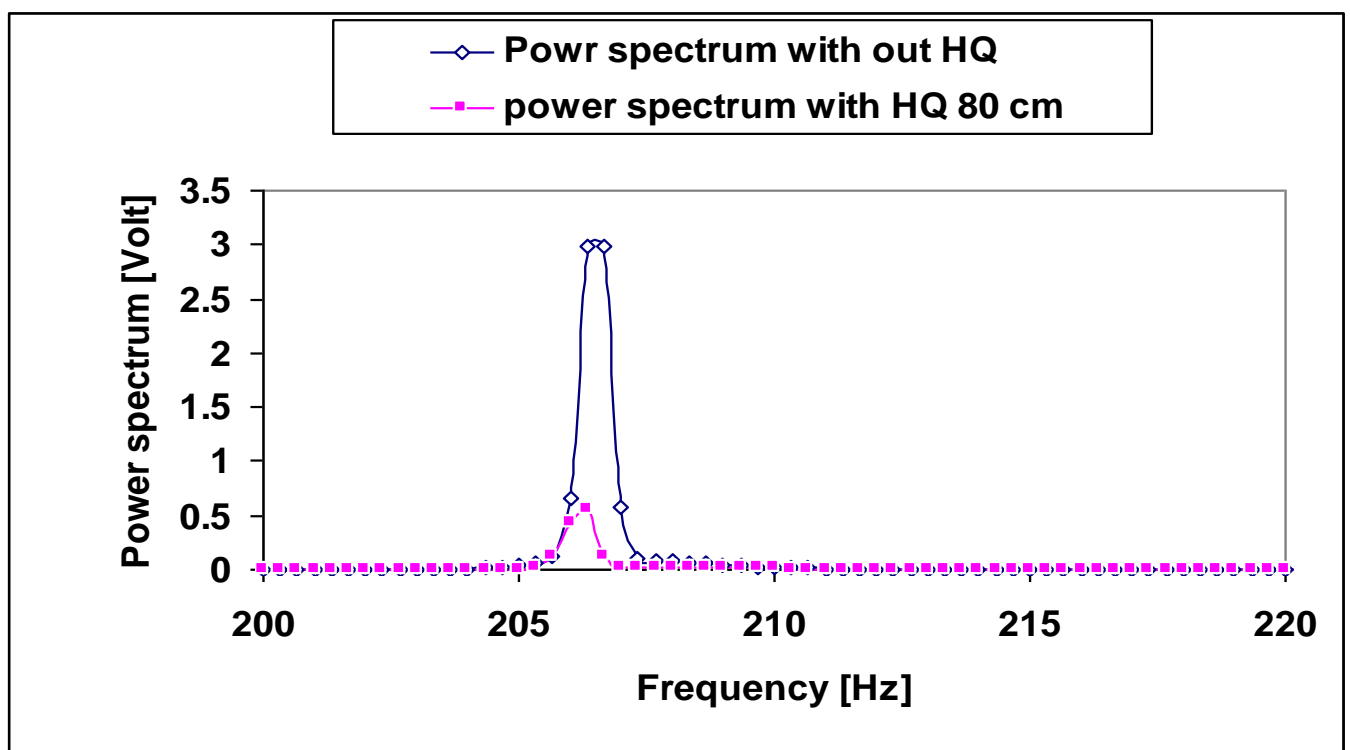

Figure (7): the power spectrum of the signal at the applied frequency of $206 \mathrm{~Hz}$ without $\mathrm{HQ}$, and with HQ-Tube length of $80 \mathrm{~cm}$ 


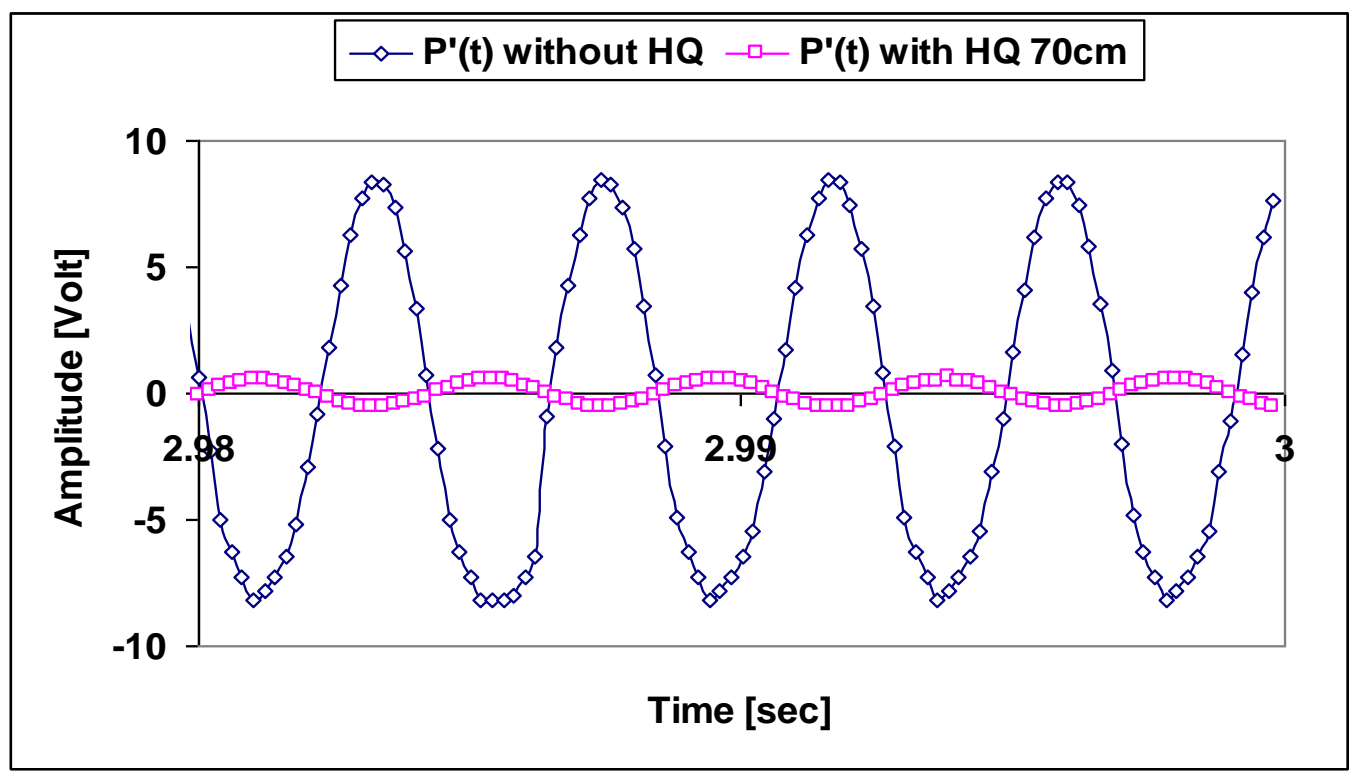

Figure (8): Time history of the acoustic signals, without and with the middle HQ at frequency of $237 \mathrm{~Hz}$, HQ-Tube length of $70 \mathrm{~cm}$

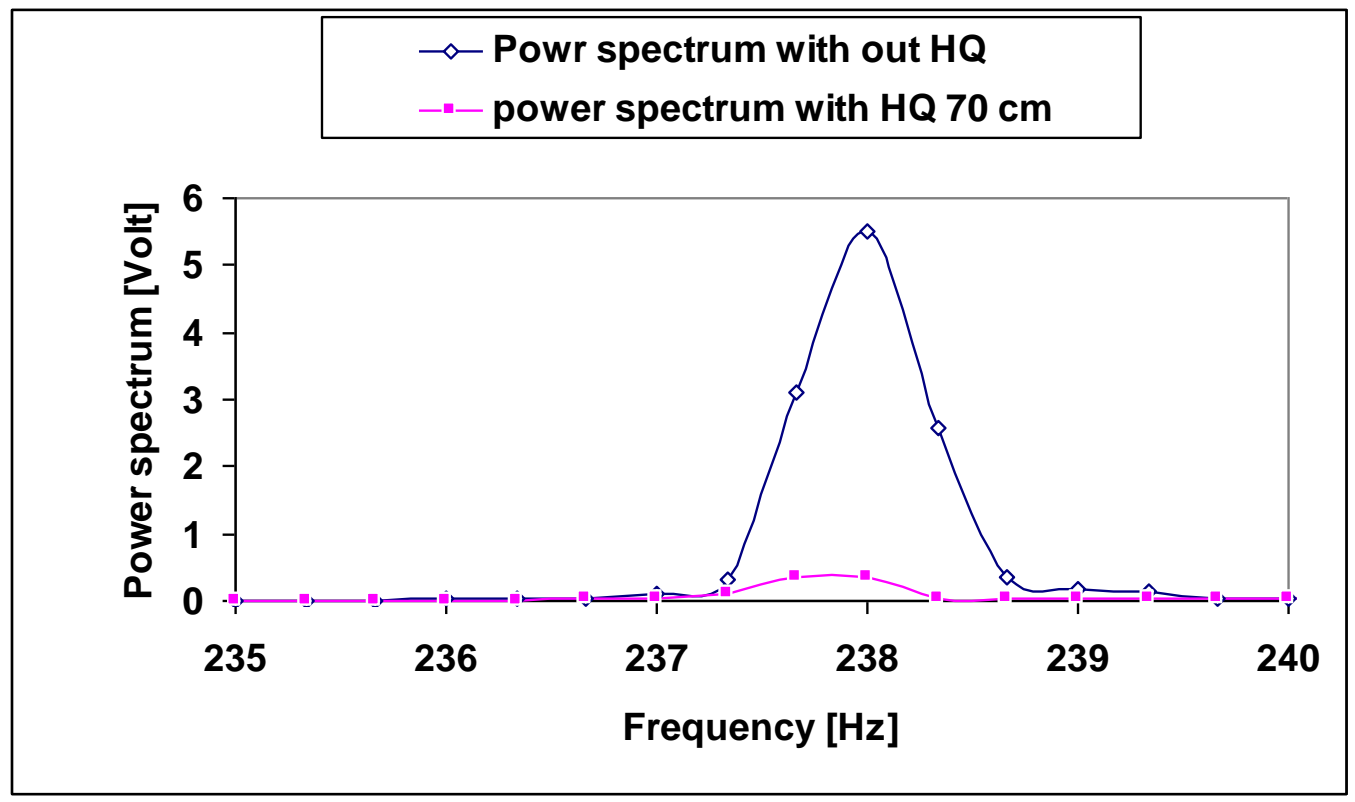

Figure (9): The power spectrum of the signal at the applied frequency of $237 \mathrm{~Hz}$ without HQ, and with HQ-Tube length of $70 \mathrm{~cm}$ 


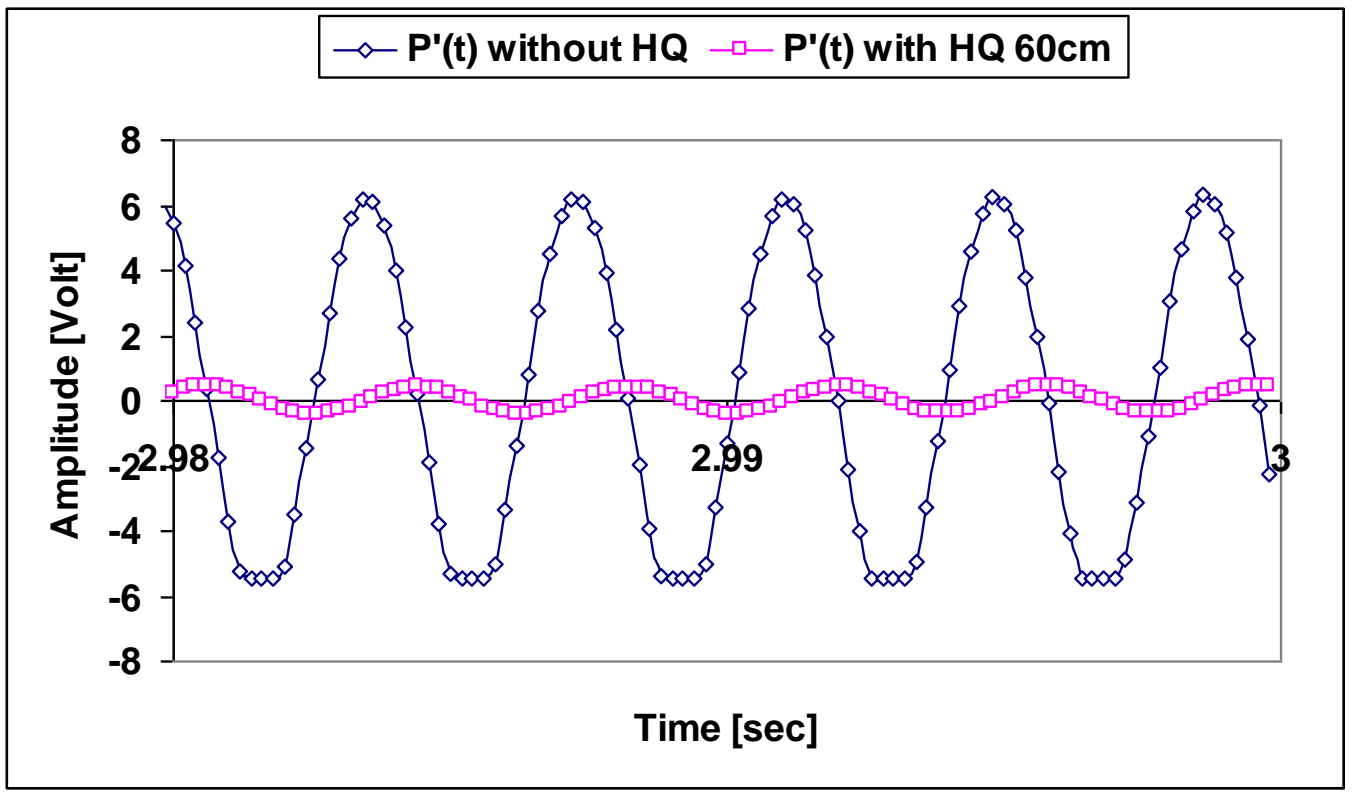

Figure (10): Time history of the acoustic signals, without and with the shortest $H Q$ at frequency of $263 \mathrm{~Hz}$. HQ-Tube length of $60 \mathrm{~cm}$

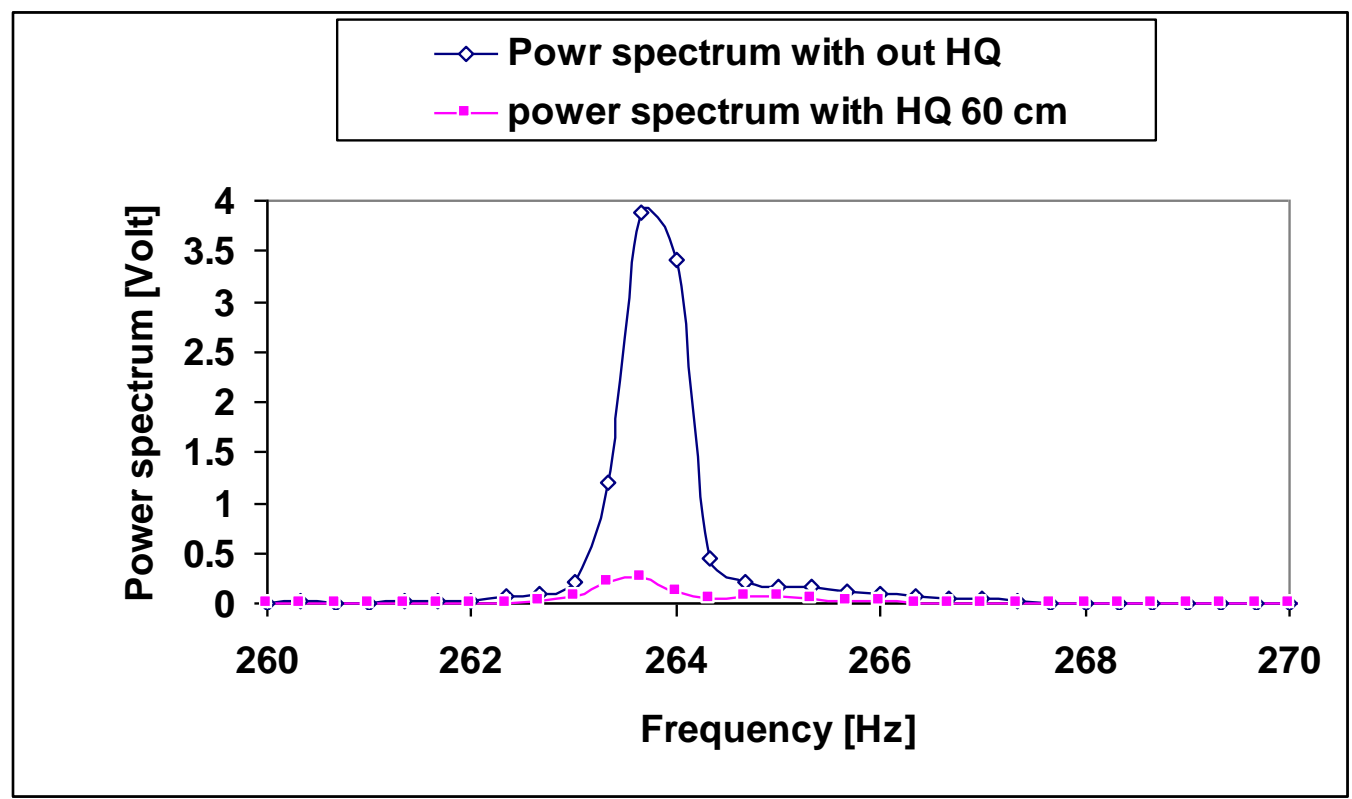

Figure (11): The power spectrum of the signal at the applied frequency of $263 \mathrm{~Hz}$ without HQ, and with HQ-Tube length of $60 \mathrm{~cm}$

\section{Conclusions}

A passive noise HQ-tubes technique is used to reduce tonal noise propagating as plane waves in ducts. Optimal tuning analysis has been achieved by using a pressure sensor (Microphone system) located in the duct at the closed end. This work presented a tuned duct with and without 
HQ-Tube technique that can be used to quiet noise in enclosed acoustic systems. It represents a powerful tool of noise controlling in tuning acoustic systems. In this paper; it has been concluded that the length of the HQ tube plays a significant role in noise reduction and control as presented in table 1, for low frequency the long tube should be used to attenuate the noise, and short HQ tube for high frequency. In addition, the collected data can be helpful in the development of modeling schemes that provide adequate prediction capabilities for the occurrence of the noise emissions or for the understanding of acoustic wave travelling in ducts attached with HQ-Tube technique.

\section{References}

- Selamet, A., Dickey, N. S., and Novak, J. M., (Nov., 1994). "The Herschel-Quincke Tube: A Theoretical, Computational and Experimental Investigation”, Journal of Acoustical Society of America, Vol. 96, No. 5, pages 3177-3185.

- Herschel, J. F. W. (1833) "On the absorption of sound by coloured media viewed in connection with undulatory theory," Philos. Mag. 3, 401-412.

- Quincke, G. (1866) "Ueber interferenz apparate für schallwallen,” Ann. Phys. Chem. 128, 177192.

- Stewart, G. W. (1928) “The theory of Herschel-Quincke tube,” Phys. Rev. 31, 696-698.

- Stewart, G. W. and Lindsay R. B., (1930) “Acoustics Van Nostrand, Princeton, NJ.

- Stewart, G. W. (1945) “The theory of Herschel-Quincke tube,” J. Acoust. Soc. Am. 17, 107-108.

- Jerome, P. Smith and Ricardo A. Burdisso (March 2002) "Experiments with Fixed and Adaptive Herschel-Quincke Waveguides on the Pratt and Whitney JT15D Engine" NASA/CR-2002211430 .

- Al-Taleb, Mohamed K. and Salem A. Farhat, Radwan N. Sharif (2017) " An Experimental Study of the Influence of the Herschel-Quincle Tube Length on Noise Attenuation" University Bulletin - ISSUE No.19- Vol. (1).

- Temkin, S. (1981). "Elements of Acoustics," Canada 164-165.

- Selamet, A., Dickey, N. S., and Novak, J. M., (Nov., 1994) "The Herschel-Quincke Tube: A Theoretical, Computational and Experimental Investigation", Journal of Acoustical Society of America, Vol. 96, No. 5, pages 3177-3185. 